\title{
Preference for predictable vs. controllable shock
}

\author{
CYNTHIA SCHEUER \\ Florida Atlantic University, Boca Raton, Florida 33432 \\ and \\ MICHAEL S. GREENBERG \\ Northwestern University, Evanston, Illinois 60201
}

\begin{abstract}
Preference for predictable vs. controllable shock was assessed through use of a symmetrical changeover procedure. Rats chose between a predictable/uncontrollable situation (CER) and an unpredictable/controllable situation (VI punishment). Consistent preference for the CER situation was found, with animals spending most of their time in that component. It was suggested that control over aversive contingencies, in the absence of predictable feedback regarding safety, is less preferable to a situation in which periods of shock and safety are well-defined.
\end{abstract}

The present experiment is an initial attempt to determine the relative preference for predictable vs. controllable shock. When predictable (signaled) shock is pitted against unpredictable (unsignaled) shock, organisms consistently choose the signaled condition, an environment in which periods of warning and safety are clearly delineated (Badia, Coker, \& Harsh, 1973). Further, the available literature has overwhelmingly demonstrated that gastric lesions are larger and more frequent in animals in which shocks or other stressors occur independently of warning signals, compared with situations in which these events are predictable (Caul, Buchanan, \& Hays, 1972; Mezinskis, Gliner, \& Shemberg, 1971; Paré \& Livingston, 1973; Price, 1972; Seligman, 1968). Investigation of other indexes of physiological damage have also shown that predictable shock is less stressful than unpredictable shock (J. P. Brady, Thornton, \& DeFisher, 1962; Paré, 1964; Weiss, 1970). Thus, the vast majority of studies have shown that predictable shocks not only are less physiologically stressful than unpredictable shocks but are also preferred to unpredictable ones.

Is control over aversive stimulation also an important source of stress reduction for the organism? One line of research that suggests that control is such a source of stress reduction comes from the learned helplessness literature. Subjects exposed to uncontrollable stress appear to show symptoms analogous to reactive depression, compared with subjects exposed to stressors that were controllable (Seligman, 1975).

A second line of evidence that suggests that controllable aversive situations may be less stressful than uncontrollable ones comes from the literature comparing organic deterioration following exposure to controllable vs. uncontrollable aversive events. Gastric lesions are typically greater following uncontrollable (inescapable or unavoidable) aversive stimulation than following similar exposure to those events when escape or avoidance is possible (Gliner, 1972; Moot, Cebulla, \& Crabtree, 1970; Weiss, 1968; Weiss, 1971a). However, unlike the studies reporting consistent preference for predictable over unpredictable aversive situations, consistent preference for control over aversive events has not been shown (Abbott \& Badia, 1979; Schuster \& Rachlin, 1968).

The present experiment was designed to investigate the relative preference for predictable vs. controllable shock. According to Seligman, Maier, and Solomon (1971), organisms are sensitive to the conditional probabilities of reinforcers following either the emission of a response or following the presentation of a stimulus. When the probability of reinforcement following a stimulus or a response is equivalent to its occurrence in the absence of that stimulus or response, we refer to reinforcement as being unpredictable. Although Seligman et al. argue that the concepts of predictability and unpredictability are typically defined within a Pavlovian conditioning framework, whereas controllability is typically defined within an instrumental training space, responding and/or its relevant feedback may act in a manner similar to external stimuli as reliable or unreliable predictors of reinforcement. Although all controllable situations involve some degree of predictability, it is possible to degrade the predictive value of the instrumental act in a variety of ways. One of these ways involves the use of a variable-interval (VI) punishment procedure. With such a procedure, no responding completely avoids shock; however, responding produces shock, but in an unpredictable fashion.

This experiment contrasted a predictable yet uncontrollable aversive situation to one that was controllable, yet relatively unpredictable. Animals were permitted to choose between a nondiscriminative VI punishment procedure superimposed on an appetitive schedule of 
water reinforcement and a standard conditioned suppression (CER) paradigm involving a fixed-duration warning signal that terminated with a brief unavoidable electric shock. The VI punishment (PUN) procedure was selected in order to degrade the predictability of any given response and to permit us to equate shock parameters with those generated by the CER condition.

\section{METHOD}

\section{Subjects}

Four male Holtzman albino rats, 90-120 days of age at the start of the experiment, served as subjects. Animals were housed individually and maintained on a 21 -h water-deprivation schedule. Subjects were tested every other day and given $10 \mathrm{~min}$ access to water following each experimental session and at a comparable time on nontest days. Session length was $1 \mathrm{~h}$ prior to introduction of the multiple CER-PUN condition when session length was increased to $3 \mathrm{~h}$.

\section{Apparatus}

Training and testing were conducted in a modified operant chamber with $.63 \mathrm{~cm}$ Plexiglas side and front walls and ceiling. Inside dimensions of the chamber were $22.7 \mathrm{~cm}$ long, $20.6 \mathrm{~cm}$ wide, and $19.5 \mathrm{~cm}$ high. A Gerbrands rat lever was located in the center of the front panel $7.2 \mathrm{~cm}$ from the grid floor of the cage. A second lever (changeover lever) consisted of a standard Lehigh Valley rat lever located on the front panel $6.5 \mathrm{~cm}$ to the left and $3.1 \mathrm{~cm}$ below the reinforcement lever. The changeover lever (R2) was inaccessible during the initial three training phases of the study. Scrambled grid shock ( $2 \mathrm{~mA} ; 5 \mathrm{sec}$ duration) was supplied by a Grason-Stadler Model 700 shock generator. A 24-V dc pilot light served as the correlated stimulus for the CER condition. The light was centered $6.5 \mathrm{~cm}$ above the reinforcement lever. White noise $(78 \mathrm{~dB})$ was supplied to the test room by a Grason-Stadler 901B noise generator through an 8-ohm speaker located in the test room. The offset of white noise served as the warning signal during CER trials.

\section{Procedure}

Prior to shaping the animals to leverpress for water, we tested the subjects for 4 days to determine the presence of any inherent reinforcing effects of the stimuli to be used as correlated cues. During these sessions, depression of the changeover lever turned the light on or off for $2 \mathrm{~min}$. Responding during these sessions was minimal (range $=$ three to seven responses), indicating no inherent reinforcing properties of either stimulus to be used as correlated cues.

Phase 1: Baseline training. Subjects were shaped to leverpress for water until stable performance was obtained on a VI 1-min schedule. For two subjects (S1 and S2), light was continuously present; for the other two subjects (S3 and S4), the light was off. Subjects were maintained on this contingency for 14-28 1-h sessions.

Phase 2: Component 1 (CER or PUN). Following the attainment of stable baseline rates, Subjects 1 and 2 were introduced to the CER component and Subjects 3 and 4 were introduced to the VI-PUN conditions in the presence of the appropriate correlated cue. In subsequent discussions, $S^{D_{1}}$ (light on) will be referred to as the correlated stimulus for CER trials and $S^{D_{2}}$ (light off) served as the correlated cue for VI-PUN trials. Shocks were presented throughout each session on a variable-time (VT) 3 -min schedule for Subjects 1 and 2 and on an identical VI 3-min schedule for Subjects 3 and 4. During CER conditions, each shock was preceded by a $30 \mathrm{sec}$ warning signal (offset of white noise); shock was thus predictable but unavoidable. During VI-PUN, shock occurred following a barpress that occurred on the average of once every $3 \mathrm{~min}$. Thus, shock was avoidable but relatively unpredictable (i.e., subjects could not predict when responding resulted in shock and when it did not). To minimize the discriminability of shock-free periods, three different VT and VI 3-min tapes were used and were changed daily. Subjects were exposed to these contingencies for an average of $181-\mathrm{h}$ sessions (range $=11-23$ ).

Phase 3: Multiple schedule. During these sessions, CER and PUN components alternated every $10 \mathrm{~min}$. During the CER component, signaled response-independent shocks occurred on a VT 3-min schedule, whereas during the PUN component, each response that occurred following an identical VI 3 -min interval was followed by shock. Subjects were maintained on the multiple CER-PUN schedule until (1) suppression was confined to the warning signal during the CER component and (2) baseline rates on the reinforcement lever had recovered to the extent that subjects were responding uniformly throughout each session.

Phase 4 changeover: Operant level. During this phase, the changeover lever was reintroduced into the test chamber and operant level changeover responding was recorded for four sessions. The reinforcement and shock contingencies were identical to Phase 3. During this phase, each response on the changeover lever had no programmed consequences, but each changeover response was recorded separately during CER and PUN components. During this phase and all subsequent conditions, subjects were exposed to each of the contingencies for a minimum of three 3-h sessions; behavior is reported for the final three sessions at each contingency.

Changeover. During changeover sessions for Subjects 1 and 2, $S^{D}$ (light off) was continuously present and the VI-PUN conditions were in effect. If the animal depressed the changeover lever, the CER component was presented for a fixed 2 min period. For Subjects 3 and $4, S_{1}$ (light on) was continuously present and the CER condition was in effect. Depression of the changeover lever turned on $\mathrm{SD}_{2}$ for $2 \mathrm{~min}$, and the punishment contingencies were in effect. For subjects to remain in changeover, they were required to depress the changeover lever following the termination of each 2 -min changeover period.

Subjects were exposed to these conditions for a minimum of four sessions (range $=$ four to six), and then they were returned to the multiple schedule (range $=$ five to six sessions) and were subsequently permitted to change over to the symmetrical condition. Thus, Subjects 1 and 2 could now change over from CER to PUN, whereas Subjects 3 and 4 could change over from PUN to CER. Animals were maintained on these contingencies for a minimum of four sessions (range $=4-9$ ) and were again returned to the multiple schedule (range $=3-13$ ). The entire procedure was repeated a second time, and each subject was permitted to change over to either CER or PUN, was returned to the multiple schedule, and then was returned to the symmetrical condition. During sessions in which the multiple schedule was in effect, changeover responses had no programmed consequences (EXT) but were recorded separately during CER and PUN components. During all phases, the baseline VI 1 -min schedule of water reinforcement remained in effect.

\section{RESULTS}

\section{Changeover Responding (R2)}

Figure 1 represents the percent of time each subject spent in changeover. The amount of time that, theoretically, would have been spent in changeover during operant-level (baseline) and extinction conditions (i.e., return to the multiple schedule) was calculated by multiplying the number of changeover responses in each component by $2 \mathrm{~min}$.

Figure 1 clearly demonstrates a strong preference for the CER situation, with subjects spending between $49 \%$ and $83 \%$ of their time in that component. Under no circumstances was there any overlap between percent time spent in CER and in PUN conditions. There was, however, a slight increase in percent time spent in 
A
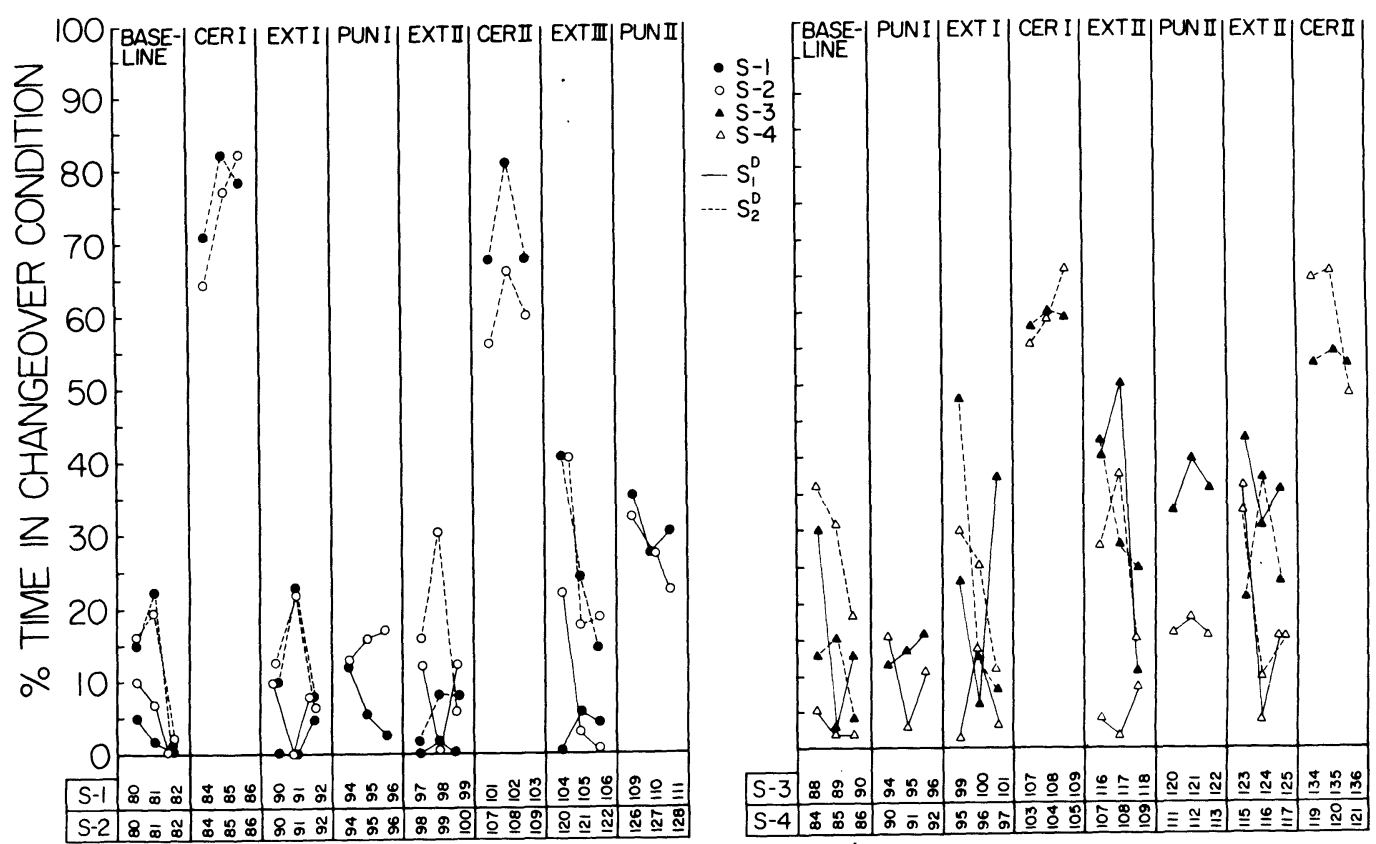

LAST THREE SESSIONS

Figure 1. Percent time spent in changeover during baseline, changeover, and extinction of changeover contingencies. Each data point represents the final three sessions at each contingency, and numbers running along the abscissa represent the session number for each subject.

PUN during the second exposure to this contingency. During the first opportunity to change over to PUN, animals were spending $3 \%-18 \%$ of their time in changeover, whereas during the second exposure, percent time in PUN increased to $16 \% 40 \%$.

\section{Baseline Responding (R1)}

Figure 2 shows response rates in each component on the reinforcement lever during the same sessions depicted in Figure 1 for changeover responding.

Response rates on the reinforcement lever remained relatively stable through all test phases of the experiment, with only a slight gradual increase observed for Subject 4 by the second extinction. There was no evidence of a photoreinforcement effect (facilitation of responding in the presence of CER) for any of the subjects. The only notable difference in rates on the reinforcement lever occurred during the PUN component (light off) for Subject 3 during the first changeover and for Subject 4 during its final exposure to changeover. Thus, since the baseline response rate for each animal in the VI-PUN component was comparable to or higher than its rate during the CER component, the temporal distribution of contact with shock was essentially identical, eliminating variations in shock density as a viable interpretation of choice for predictable to that of controllable shock.

\section{DISCUSSION}

The data clearly demonstrated that predictability of shock is preferable to controllability of shock, as all subjects showed a clear preference for the CER situation compared with VI-PUN. Although the present findings suggest that predictable shock is preferred to controllable shock, they do not conform

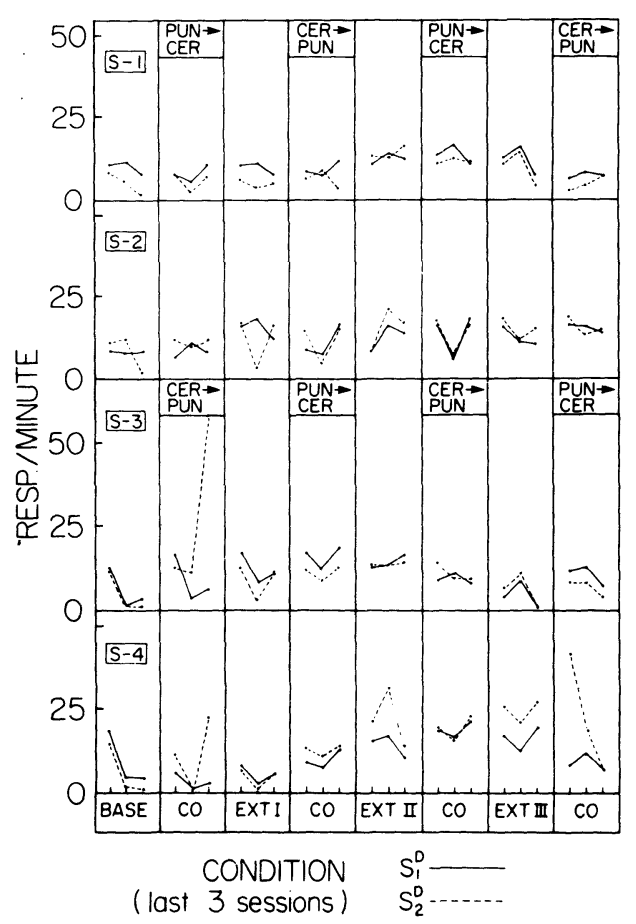

Figure 2. Responses per minute on the water reinforcement lever (R1) during the same sessions as represented in Figure 1. 
to the findings in the physiological literature that report lowered indexes of organic deterioration in situations in which subjects have control over aversive stimulation (Gliner, 1972; Moot et al., 1970; Weiss, 1968, 1971a). Each of these investigations, however, incorporated paradigms in which the response that effectively controls shock signals shock-free periods. In situations in which the predictability of the response that effectively controls shock has been degraded, higher indexes of physiological stress have been found in operant subjects, compared with their yoked counterparts (Barbaree \& Harding, 1973; J. V. Brady, Porter, Conrad, \& Mason, 1958; Pare, 1971; Tsuda \& Hirai, 1975; Weiss, 1971b). That is, when a given response fails to produce immediate feedback of shock-free periods, a higher incidence of gastric lesions occurs in escape or avoidance, compared with yoked subjects.

We essentially support Weiss (1971c) in his view regarding the importance of discriminable "coping" responses in the attenuation of physiological symptoms of stress and further suggest that, if control is important to an organism, it is so only when a high degree of predictability is present as well. That is, instrumental control of responding per se may be preferred to no control only when the instrumental response itself is a reliable predictor of shock termination and/or discriminable shock-free periods.

It should be mentioned that, in the present design, we required animals to choose between a VI-PUN procedure and a CER condition, and thus, we may have contrasted a severe conflict against one that is less severe, since avoidance of shock necessarily postpones the presentation of positive reinforcement. A less direct interaction between responding and reinforcement occurs during CER trials. However, relative severity of each type of conflict situation cannot be made a priori, independently of choice behavior. In the same context, it should be noted that Schuster and Rachlin (1968) obtained no differential preference for a Pavlovian vs. an operant conflict situation when responseindependent shocks occurred in the absence of warning stimuli, even though greater suppression occurred in the terminal link signaling VI-PUN. Nonetheless, it would be advantageous to select a somewhat different paradigm as our controllable situation, one that did not require the organism to relinquish positive reinforcements in order to preclude presentation of an aversive contingency.

Choice for the CER procedure over PUN may have also been influenced by the relative degree of predictability vs. the relative degree of controllability of each event. The CER procedure involves perfect predictability of shock [i.e., $\mathrm{p}$ (shock $/$ signal $=1.0$ and the $p($ shock $/ \overline{\text { signal }}=.0]$. In contrast, the PUN procedure involves less than perfect control. In this situation, $\mathrm{p}($ shock$/$ response $)=.0$, but the $\mathrm{p}($ shock/response) is much less than 1.0. Our results may have shown merely that perfect prediction is preferable to imperfect control.

In summary, our results suggest that control over aversive events is less preferable to predictability of those same events when using a changeover design. We are currently investigating the extent to which other choice paradigms generate similar findings. Current animal research involving choice of various aversive contingencies uses changeover or crossover procedures exclusively. These procedures are essentially escape paradigms, situations in which the organism is motivated by a state of either acute or chronic anxiety. Little is known regarding preference for various aversive contingencies when choice is assessed in advance of ongoing aversive motivation.

\section{REFERENCES}

Аввотт, B., \& BadiA, P. Control over noxious events and choice. Animal Learning \& Behavior, 1979, 7, 149-156.
Badia, P., Coker, C., \& Harsh, J. Choice of higher density signalled shock over lower density unsignalled shock. Journal of the Experimental Analysis of Behavior, 1973, 20, 47-55.

Barbaree, H. E., \& Harding, R. K. Free-operant avoidance behavior and gastric ulceration in rats. Physiology \& Behavior, 1973, 11, 269-271.

Brady, J. P., Thornton, D. R., \& DeFisher, D. Deleterious effects of anxiety elicited by conditioned pre-aversive stimuli in the rat. Psychosomatic Medicine, 1962, 24, 590-595.

Brady, J. V., Porter, R. W., Conrad, D. G., \& Mason, J. W. Avoidance behavior and the development of gastroduodenal ulcers. Journal of the Experimental Analysis of Behavior, 1958, 1, 69-72.

Caul, W. F., Buchanan, D. C., \& Hays, R. C. Effects of unpredictability of shock on incidence of gastric lesions and heart rate in the immobilized rat. Physiology \& Behavior, 1972, 8, 669-672.

Gline R, J. A. Predictable versus unpredictable shock: Preference behavior and stomach ulceration. Physiology \& Behavior, 1972, 9, 693-698.

Mezinskis, J., Gliner, J., \& Shemberg, K. Somatic response as a function of no signal, random signal, or signalled shock with variable or constant durations of shock. Psychonomic Science, 1971, 25, 271-272.

Moot, S. A., Cebulla, R. P., \& Crabtree, J. M. Instrumental control and ulceration in rats. Journal of Comparative and Physiological Psychology, 1970, 71, 405-410.

PARÉ, W. The effects of chronic environmental stress on stomach ulceration, adrenal function, and consummatory behavior in the rat. Journal of Psychology, 1964, 57, 143-151.

PARÉ, W. Six-hour escape-avoidance work shift and production of stomach ulcers. Journal of Comparative and Physiological Psychology, 1971, 74, 459-466.

Paré, W., \& Livingston, A., JR. Shock predictability and gastric secretion in the chronic gastric fistula rat. Physiology \& Behavior, 1973, 11, 521-526.

PrICE, K. P. Predictable and unpredictable shock: Their pathological effects on restrained and unrestrained rats. Psychological Reports, 1972, 30, 419-426.

SChUSTER, R., \& RACHLiN, H. Indifference between punishment and free shock: Evidence for the negative law of effect. Journal of the Experimental Analysis of Behavior, 1968, 11, 777-786.

Seligman, M. E. P. Chronic fear produced by unpredictable electric shock. Journal of Comparative and Physiological Psychology, 1968, 66, 402-411.

Seligman, M. E. P. Helplessness. San Francisco: Freeman, 1975.

Seligman, M. E. P., Maier, S. F., \& Solomon, R. L. Unpredictable and uncontrollable aversive events. In F. R. Brush (Ed.), Aversive conditioning and learning. New York: Academic Press, 1971.

Tsuda, A., \& Hirai, H. Effects of psychological factor on stress pathology in rats: The difficult effect of coping response task. Japanese Psychological Research, 1975, 17, 119-132.

Weiss, J. M. Effects of coping responses on stress. Journal of Comparative and Physiological Psychology, 1968, 65, 251-260.

WEISs, J. M. Somatic effects of predictable and unpredictable shock. Psychosomatic Medicine, 1970, 32, 397-408.

WEISS, J. M. Effects of coping behavior in different warning signal conditions on stress pathology in rats. Journal of Comparative and Physiological Psychology, 1971, 77, 1-13. (a)

Weiss, J. M. Effects of coping behavior with and without feedback signal on stress pathology in rats. Journal of Comparative and Physiological Psychology, 1971, 77, 22-30. (b)

Weiss, J. M. Effects of punishing the coping response (conflict) on stress pathology in rats. Journal of Comparative and Physiological Psychology, 1971, 77, 14-21. (c)

(Received for publication March 8, 1982.) 